\title{
Applicability of Moyer's prediction tables to estimate the mesio-distal diameter of canines and premolars
}

Amanda de Sousa Galdino ${ }^{1}$, Tânia Braga Ramos ${ }^{1}$, Vitor Marques Filgueiras ${ }^{2}$, Rosa Helena Wanderley Lacerda ${ }^{2}$

1. Brazilian Dentistry Association/ Paraiba, Brazil

2. Paraiba Federal University, University Hospital, Cleft Center, Brazil

\section{Abstract}

Objective: The aim of this study was to verify the applicability of Moyer's prediction tables to estimate the mesio-distal diameter of canines and pre-molars in a population of North-Eastern Brazil. Materials and Methods: A sample of 100 plaster moulds of 12-18-year-old patients was selected from the dental archives of the Brazilian Association of Orthodontists Dental School Clinic in the city of João Pessoa, State of Paraiba. Analyses were performed with R software (version 3.1.3). The upper and lower canines and premolars on both sides of the arch were measured. Data Analysis: Linear regression analysis was used to assess the closeness of the estimated values in each percentile of Moyer's prediction table. Analyses were performed at a significance level of $5 \%$. Results: Gender dimorphism $(P<0.001)$ was found in both upper and lower arches. In the upper arch, the best regression models for data analysis of female, male and both were, respectively, p5 and p6", p25 and p35, and p35 and 75, whereas in the lower arch were p15, p35 and p75, with "p75 being the best-fitted percentile following application of correction equations for both genders. Conclusions: The Moyer's prediction table can be applied for estimating the mesio-distal diameters of canines and pre-molars, provided that a correction factor is used for the population under study.
Citation: Galdino AS, et al. (2019) Applicability of Moyer's prediction tables to estimate the mesio-distal diameter of canines and premolars. Dentistry 3000. 1:a001 doi:10.5195/d3000.2019.86 Received: October 7, 2018

Accepted: December 6, 2018

Published: June 26, 2019

Copyright: (C2019 Galdino AS, et al. This is an open access article licensed under a Creative Commons Attribution Work 4.0 United States License.

Email:rhelenawanderley@msn.com

\section{Introduction}

The majority of malocclusions are related to an imbalance between mesio-distal diameter of the teeth and their bone support (1). This statement was observed by Angle (1899), who classified the malocclusions of the teeth. Antero-posterior malocclusions were classified as follows: Class I normal relationship between maxilla and mandible; Class II - the maxilla is more anteriorly positioned than the mandible; and Class III - the mandible is more anteriorly positioned than the maxilla $(2,3)$.

As there are several changes within the alveoli due to bone growth during the phase of mixed dentition, the majority of malocclusions occur in these sites. Also, because some teeth (e.g. canines and pre-molars) are still unerupted, it is complicated to evaluate any discrepancy between teeth and bone supports. In this phase, it is important to estimate the size of the unerupted permanent teeth in order to evaluate whether the dental sockets will correspond to the dental volume after eruption (4).

There are some methods to evaluate discrepancies and the Moyer's method is one of the most used as it has some advantages, such as simplicity in usage, quickness and no need of periapical radiography (5). The Moyer's analysis is based on a statistical method in which one can predict the sum of mesiodistal measurements of unerupted canines and pre-molars through its relationship with the sum of the mesio-distal measurements of the already erupted lower incisors (6). However, the method proposed by the author was based on a North-American population, and thus its accuracy may vary for populations from other countries (7).

The objective of this work was to assess the applicability of the Moyer's prediction tables to
(cc)BY ULIS D-Sorle
New articles in this journal are licensed under a Creative Commons Attribution 4.0 United States License.

This journal is published by the University Library System, University of Pittsburgh as part of its D-Scribe Digital Publishing Program and is cosponored by the University of Pittsburgh Press. 
estimate the mesio-distal diameter of canines and premolars in a population of NorthEastern Brazil.

\section{Materials and Methods}

\section{Samples}

- All the plaster moulds of 12-18-year-old patients who attended the Brazilian Association of Orthodontists Dental School Clinic in the city of João Pessoa, State of Paraiba, between 2010 and 2015 were evaluated for selection, resulting in a sample of 100 moulds according to inclusion and exclusion criteria. Were included plaster moulds in good conditions, that is without fractures or distortions, with all the teeth should be erupted (i.e. dentition from first molar to first molar); in patients aged between 12 and 18 years old. Were excluded teeth with anomalies in shape or size and evidence of caries or proximal restorations in the teeth to be measured.

The present study was approved by the local human research ethics committee according to protocol number 44133515.6 .0000 .5180 and resolution number 196 of
1996 by the National Health Committee and National Ethics Committee of the Ministry of Health.

Pilot Study

A pilot study was performed to calibrate the examiner, with Kappa test being 0.835 at significance level of $5 \%$ and confidence interval of $95 \%$. In the pilot study, a total corresponding $10 \%$ of the total sample, and therefore 10 models, evaluated twice, by the same examiner with an interval of 10 days and only the research was initiated after obtaining the concordance index intra-examiner above 0.7, considered good agreement and therefore means the examiner was calibrated and fit for research development. These models did not part of the survey sample.

Measurement

The mesio-distal diameter of the lower incisors of each plaster mould was measured to obtain the sum of this space. Next, the measurements of upper and lower canines and pre-molars were performed on both sides based on the largest distances between the contact points of the proximal surfaces. A digital calliper (Digimess, São Paulo, Brasil) was used for the measurements ( calibration $0,005 \mathrm{~mm} / 0,002 "$ ), being positioned in parallel to the occlusal surface and perpendicular to the axis of the tooth.

The sample was divided into groups of 10 moulds each and they were individually measured, avoid the vies of the fatigue that could compromise the quality of the measurement.

Next, the sum of the measurements of upper and lower canines and premolars were transferred to Excel spreadsheets, which also included gender and age as variables.

\section{Statistical Analysis}

Normality distribution test was applied to the mean values obtained from the total measurements of the mesio-distal diameter of canines and premolars, resulting in non-normal distribution for both females $(P=$ 0.031; Shapiro-Wilk) and males ( $P$ $<0.001$; Kolmogorov-Smirnov) as well as in complete distribution for both genders $(P<0.001$; Kolmogorov-Smirnov).

In view of the results of the normality distribution test, the Mann-Whitney test was performed to assess the existence of gender dimorphism between females and males regarding the mean measurements of canines and pre-molars, showing presence of dimorphism $(P<0.001)$ in both upper and lower arches.

Next, the Spearman's correlation coefficients were calculated between mean values and Moyer's percentiles for genders separately.

In view of the significant results for correlation analysis, a linear regression analysis was 
conducted to assess the prediction of measurements by using the Moyer's percentiles, including generation of determination coefficient, which was the parameter adopted to chose the percentiles closer to the actual values found in the population of the city of João Pessoa in both males and females as well as in the general population.

For each mould in each analysis, the following was verified: error normality, homoscedasticity of residuals, error independence, linearity of predicted mean values and absence of aberrant, leverage or influence values. All the models proposed met the requisites of a fitted linear regression model.

All the analyses were conducted by using the statistical software R (version 3.1.3) at significance level of $5 \%$.

\section{Results}

Table I show the measurements of canines and pre-molars regarding gender dimorphism, respectively, in the upper and lower arches.

\section{TABLES}

\section{Upper Arch}

The results listed in Table II show that there are significant correlations between actual values and those estimated by the Moyer's percentiles for males and females separately and for both genders, with stronger correlations being observed in males only, followed by both genders. For assessment of a correlation, values above 0.8 are considered as having excellent internal consistency. Prieto \& Muniz (2000) suggest that, for samples smaller than 200 subjects, values above 0.6 are considered adequate enough so that the Spearman's ranking can be the following: $0.70-0.79$ (adequate); 0.80-0.84 (good) and above 0.85 (excellent) (8).

\section{TABLE II}

In addition, the correlation values are positive, meaning that the values observed follow the actual ones so that the higher the actual values, the higher the estimated values.

\section{Linear Regression Analysis}

The best models of linear regression obtained for analysis of data regarding females, males and both genders were, respectively, p5 and p65, p25, and p35 and p75. With regard to equal models regarding the determination coefficient for assessment of females and both genders, the models were diagnosed to decide which the best one was.

In this way, standardised residuals, Cook's distance and residual square sum were assessed to verify the existence of differences between the models for these parameters.

\section{TABLE III}

The smaller the standardised errors, the Cook's distance and the residual square sum, the better the models because of the smaller distances between actual values and estimated ones. Therefore, there was no difference between the models generated for females, with the $75^{\text {th }}$ percentile model being the best to predict space for unerupted teeth in both genders due to the lowest residual square sum.

In this way, one can observe that the $5^{\text {th }}$ percentile $\left(r^{2}=0.624\right)$ and $65^{\text {th }}$ percentile $\left(r^{2}=0.750\right)$ for female gender had the same parameters; the $25^{\text {th }}$ and $75^{\text {th }}$ percentiles were the best to predict measurements, respectively, for male gender and both genders. However, in view of the low rate of adjustment of the models for the female gender $(62.4 \%)$, it is suggested that correction factors should be used for the best models for male gender and both genders, and in the case of females, it is suggested the use of parameters for estimation in both genders. The correction factors for these models are described below in Table IV, with respective rates of adjustment.

\section{TABLE IV}

\section{Lower Arch}

Assessment of correlation between mean values of premolars and each percentile by gender and regarding the whole set of data.

These results indicate that there are significant correlations between actual values and estimated ones by using the 
Moyer's percentiles for males and females separately as well as for both genders, with stronger correlations being observed for data on males followed by data on both genders. In addition, the positive correlation values mean that the values observed correspond with the actual values so that the higher the actual values, the higher the estimated ones ( Table V).

\section{Linear Regression Analysis}

The best models of linear regression obtained for analysis of data regarding females, males and both genders involving the predictor variable were, respectively, $\mathrm{p} 15$ and $\mathrm{p} 35, \mathrm{p} 75$. By observing the values obtained for the different parameters of each model in each analysis (i.e. female, male and both), one can realise that they are equal.

In this way, standardised residuals, Cook's distance and residual square sum were assessed to verify the existence of differences between the models for these parameters. However, according to Table VI, one can observe that there are differences neither in the mean values of residuals, nor in the mean values of Cook's distance and residual square sum and respective standard deviations between the models of percentiles p15, p35 and p75 in all analyses.

\section{TABLE V and VI}

The smaller the standardised errors and the Cook's distance, the better the models because of the smaller distances between actual values and estimated ones. Therefore, there was no difference between the models generated for females, with the $75^{\text {th }}$ percentile model being the best to predict space for unerupted teeth in both genders due to the lowest residual square sum. Therefore, Table VI shows that there was no difference between the models generated for each assessment (i.e. female, male and both).

In this way, one can realise that any percentile (i.e. p15, p35 and 075) can be used to estimate the space for pre-molars, provided that the following correction factors are used for the population under study.

\section{TABLE VII}

\section{Discussion}

The success of the orthodontic therapy depends mainly on the correct diagnosis (9), thus the treatment planning should include key elements of an early diagnosis. The methods to predict the mesiodistal diameter of permanent teeth and the discrepancy between moulds play an important role in this context, since space problems can be diagnosed and treated even during the mixed dentition in a less invasive manner (10). In view of this, the present study was aimed at assessing one of the most used methods by surgeondentists and its applicability in a study population.

The presence of gender dimorphism (Tables I) in the findings of our study is corroborated by several works in the literature, that is, showing that men have larger upper and lower dental arches than women $(11,12,13)$. Yamaguti \& Vasconcelos (2005) also reported that there is gender dimorphism as all the mesio-distal dental dimensions of male individuals are greater than those of females (14).

By applying the Moyer's prediction table to our population, the correlation coefficients revealed that the percentiles corresponding to the best regression models in the upper arch for males and females separately as well as for both genders were $\mathrm{p} 5$ and $\mathrm{p} 65$, p25, p35, and p75, with the $75^{\text {th }}$ percentile being the best model for both genders. In the lower arch, the percentiles p15, p35 and p75 had the best regression models. Some studies $(15,16,17)$ showed that the Moyer's table could not be used in their populations, since the actual values did not correspond to the estimated ones, by either overestimating or under-estimating the values, as in the studies by Farret et al. and Cabral \& Pessoa $(16,17)$, respectively.

However, by means of statistical tests, we found that the Moyer's tables can be applied to different populations other than that used in the original study, provided that they are adjusted by using correction factors. This was corroborated by a similar study performed in the North-Eastern Brazil, with the probability tables being shown to be reliable for use 
in Caucasian individuals (12), but it is necessary to use correction factors with an equation (Table IV), as for lower arch: P75 - 25.094 $+2.019 \times 20.4=16.09$.

Fida \& Bherwani (18) (2011) compared the use of the linear equations developed for the North-American population to that developed by them for a population of Pakistani children and also compared the results to those found by Moyers and Tanaka \& Johnstone, reporting no significant differences. However, the authors concluded that the methods used for the NorthAmerican population did not fit to the Pakistani one, leading to the need to develop other method $(18,19)$. In a study on Caucasian Brazilians, Melgaço, Araujo \& Ruelas (2006) also used linear regression equations and reported that the prediction method was good in determining the width of canines and pre-molars.

The Moyer's prediction tables have probabilities ranging from 5 to 95 percent, but the author suggests that a 75-percent level should be used to estimate the values in order to prevent crowding (21). In the study by Cabral (2002), the values of the Moyer's table were used at a 50percent level, since they are mean values and t-test compares them $(16,17)$. In this study, such a percentile was also chosen because it represents a high adjustment rate, that is, $\mathrm{R}^{2}=76.3$ percent. However, the adjustment rate was low for females and for this reason we suggest its use to standardise the use of the equation for both genders.

TABLE VIII and IV

From these results, we propose that the Tables $\mathrm{V}$ and $\mathrm{VI}$ should be used in patients of North-Eastern Brazil in order to facilitate the treatment.

Based on the results found, we have concluded that:

1) There was gender dimorphism between the statistical models for females and males, with the sum of the mesio-distal diameters of incisors, canines and pre-molars in men being greater than that in women regarding upper and lower arches;

2) The correlation tests and linear regression analyses showed that the best regression models to assess data from both genders was those using the $75^{\text {th }}$ percentile;

3) The Moyer's table can be used to predict the mesiodistal diameter of canines and pre-molars in the population of NorthEastern Brazil, provided that it is adjusted by means of a correction factor.

\section{References}

1. Patterns of dental crowding in the lower arch and contributing factors. A statistical study. Shigenobu N, Hisano M, Shima S et al. Angle Orthod; 2007;15:303-
310.

https://doi.org/10.2319/00033219(2007)077[0303:PODCIT]2.0. $\mathrm{CO} ; 2$

2.Classification of Malocclusion. Angle EH. Dent Cosmos; 1899; 41: 248-64.

3. Avaliação comparativa de três métodos para cálculo do espaço requerido na dentição mista . Oliveira MVP, Ruellas MM, Oliveira AC. . Revista Odonto Ciência - Fac. Odonto/PUCRS; 2007:148-153.

http://scholar.google.com.br/scho lar_url?url=http\%3A\%2F\%2Fwww. matheuspithon.com.br\%2Fv2\%2F wpcontent\%2Fuploads\%2Fodonto2007-226.pdf\&hl

4. Análise da dentição mista: tomografia versus predição e medida radiográfica. Felício LG, Ruellas ACO, Bolognese AM, Santana EF, Araújo MTZ. Dental Press J Orthod; 2010; 15: 159-165.

5. New, fast, and accurate procedure to calibrate a 2 dimensional digital measurement method. Paredes V, Gandia JL, Cibrian R. Am J Orthod Dentofacial Orthop; 2005; 127: 518-519.

6. Handbook of Orthodontics for the Student and General Practioner. Moyers RE.. 2a ed. Chicago; Year Book Medical, 1963.

7. Orthodontic probability tables forblack patients of Africa descent: mixed dentition analysis. Schirmer UR, Wiltshire, WA. Am J OrthodDentofacial Orthop.;1997; 112: 545-551. 
8. Un modelo para evaluar la calidad de los tests utilizados en España. Prieto G; MUÑIZ, J.; Disponível em: $<$ http//www.cop.es/tests/modelo. htm>.

9. Prediction of the mesiodistal width of unerupted permanent canines and premolars: a statistical approach. Boboc A, Dibbets J. Am J Orthod Dentofacial Orthop; 2010; 137: 503-507.

10. Comparação de diferentes incidências radiográficas para a predição de tamanho dentário na dentição mista. Gonçalves TS, Menezes LM, Lima, EMS. Revista Ortodontia Gaúcha; 2011;15: 1-12.

11. Determinação do diâmetro mésio-distal de dentes caninos e pré-molares em indivíduos brasileiros da região de Araraquara. Paixão RF, Cordeiro, RCL, Gandini junior, L. R Dental Press Ortodon Ortop Facial; 2002; 7:45-43.

12. Applicability of moyers' probability table in the population of the northeast of Brazil. Pithon MM , Lacerda-Santos R, Araujo JTS, Coqueiro RS. Biosci. J. 2015; 31: 311-318.

13. Mixed Dentition Space Analysis in Kodava Population: $A$ Comparison of Two Methods. Ramesh N, Reddy MS, Palukunnu B, Shetty B, Puthalat U. Journal of Clinical and Diagnostic Research; 2014; 8: 01-06.

14. Determinação das medidas dentárias mésio-distais em indivíduos brasileiros leucodermas com oclusão normal. Yamaguto OT, Vasconcelos MHF. Dental Press Ortodon Ortop Facial; 2005; 10: 99-107.

15. Aplicabilidade da tabela de Moyers na predição do tamanho dos caninos e pré-molares em brasileiros leucodermas descendentes de europeus. Farret MMB, Jurach EM, Lopes LFD, Porto SS, Porto VS.Ortodontia; 2005; 38: 163-168.

16. Análise de dentição mista Avaliação das tabelas de Moyers em Campina Grande, Paraíba. Cabral ED, Guedes AP. J Bras Ortodon Ortop Facial; 2002; 7: 235-237.

17. Evaluation of Moyers' tables to estimate the width of canine and premolars: a study in Natal-RN. Cabral ED, Caldas JA, França A, Cabral Filho H,Caldas SGFR. J. bras. ortodon. ortop. Facial; 2004; 9:3740.

18. Development of a prediction equation for the mixed dentition in a Pakistani sample. Bherwani AK, Fida M. American Journal of Orthodontics and Dentofacial Orthopedics; 2011;140: 626-632.

19. The prediction of the size of unerupted canines and premolars in a contemporary orthodontic population. Tanaka MM, Johnston LE. J Am Dent Assoc;1974; 88: 798801.

20. Applicability of Three Tooth Size Prediction Methods for White Brazilians. Melgaço CA, Araújo MT, Ruellas ACO. Angle Orthodontist; 2006; 76: 644-649.
21. Applicability of Moyers analysis in mixed dentition: $A$ systematic review. Galvão MAB, Dominguez GC, Tormin ST, Akamine A, Tortamano A, Fantini SM. Dental Press J Orthod; 2013; 18:100-105. 